Access to this work was provided by the University of Maryland, Baltimore County (UMBC)

ScholarWorks@UMBC digital repository on the Maryland Shared Open Access (MD-SOAR) platform.

Please provide feedback

Please support the ScholarWorks@UMBC repository by emailing scholarworks-group@umbc.edu and telling us what having access to this work means to you and why it's important to you. Thank you. 


\title{
Create Social Responses to a Changing Environment
}

\section{Allison Gibson, Nancy Kusmaul, Skye Leedahl, \& Victoria M. Rizzo}

\begin{abstract}
Communities across the globe, including the United States, face unprecedented environmental challenges influenced by factors such as climate change and an increasing global population. This chapter will focus specifically on natural disasters. While natural disasters have always existed, the current uptick in the frequency of disaster events, growing evidence that disasters negatively affect older adults disproportionally, and a larger number of older adults comprising the world's population than any other age group, make it necessary to consider the specific impacts disasters have on the older adult population. Older adults have unique needs during disasters due to vulnerabilities common in late-life as well as social isolation. This chapter details the needs of older adults across the disaster event phases: pre-disaster mitigation and preparedness, during and post-disaster response, and long-term disaster recovery. The chapter concludes with future steps for social work research, policy and practice.

Key Words: Environmental Justice; Natural Disaster; Disaster Response; Disaster Recovery; Manmade Disaster

\section{Grand Challenge: Create Social Responses to a Changing Environment}

The Grand Challenge Create Social Responses to a Changing Environment aims to strengthen individual and community capacities to anticipate, respond, and adapt to environmental changes (i.e., natural disasters, pollution, climate change, and an increasing global population). Challenges caused by our changing environment negatively affect individuals and communities, forcing them to breathe unhealthy air, drink tainted water, or ingest toxic chemicals. These harmful impacts are environmental and social justice issues particularly for
\end{abstract}


vulnerable populations, including older adults, the poor, children, and racial and ethnic minorities. This Grand Challenge calls on social workers to collaborate with multiple disciplines and societal sectors (i.e., business, government, policy, health care, and not-for-profit) to engage in activities focused on environmentally displaced populations, disaster risk reduction, and environmental justice.

\section{Overview}

The occurrence of natural disasters, large events that threaten lives and/or possessions of those in affected areas, is on the rise (Mooney \& Dennis, 2018). Each year, people all over the world experience various natural disasters, such as hurricanes, floods, earthquakes, and fires, which affect their ability to function with day-to-day activities. With climate change, the number of natural disasters is on the rise with record incidences recorded over the past few years (National Oceanic and Atmospheric Administration, 2018). In 2016, the United States broke previous records with 15 major weather and climate disaster events followed by 16 major weather and climate disaster events in 2017 (National Oceanic and Atmospheric Administration, 2018). Internationally, natural and environmental disasters affected 1.7 billion individuals between 2005 and 2014. The estimated cost of these disasters was $\$ 1.4$ trillion (United Nations Office for Disaster Risk Reduction, 2015). In 2017, 962 million people aged 60+ comprised 13\% of the global population (United Nations, 2018). This demographic shift towards an aging population necessitates profound economic and social changes, including disaster preparedness and response (Murdock, Cline, Zey, Perez, \& Jeanty, 2015).

In disaster preparedness and disaster response, communities, and caregivers, should address the distinct needs of older adults. For example, many older persons are diagnosed with chronic health conditions that are compounded by sensory deficits, (e.g., limited vision or 
hearing), reduced mobility, cognitive decline, or mental health conditions such as depression or anxiety. Additionally, older adults who live in rural areas may be isolated, have limited social networks or family supports, and/or fewer economic resources than those in more urban areas.

Because of these age-related risks, older persons are often exposed to more danger, encounter more life-threatening challenges when trying to evacuate or relocate, are less likely to receive disaster warnings, and often experience greater financial losses in natural disasters (Acierno, Ruggiero, Kilpatrick, Resnick \& Galea, 2006; Aldrich \& Benson, 2008; Sakauye, Streim, Kennedy, Kirwin, Llorente, Schultz, et al., 2009). Further, older adults experience significant anxiety about their ability to evacuate during a future disaster or terrorist attack, due to immobility or infirmity (Monahan \& Lurie, 2007). Older adults also experience more difficulty recovering from disasters than younger persons, particularly if they have limited individual, social, and financial resources. Additionally, they are more likely to suffer significant financial losses after disasters than younger groups (Al-Rousan, Rubenstein, \& Wallace, 2014), and frequently cannot absorb disaster-related expenses due to pre-existing financial constraints and ability to recoup losses (Powell, Plouffe, \& Gorr, 2009; Walsh, Gibson \& Brown, 2016).

Older adults, specifically the frail and/or homebound, are particularly vulnerable as a result of needs including the accessibility of their home versus that of a shelter, safe means to store vital medications, the availability of family members and/or paid caregivers, and transportation. In all types of natural disaster, including recent hurricanes and fires, (Nedelman, 2017), older adults still disproportionality experience ill effects and mortality, making it evident that the needs of this population have not been fully addressed. For example, in 2005 when Hurricane Katrina struck southeastern Louisiana and coastal Mississippi, "of the 1,836 residents who lost their lives, $71 \%$ were over 60 -years-old and $47 \%$ were over 75 -years-old" (Centers for 
Disease Control, 2006, p.1). These statistics ignited conversations across the fields of public health, medicine, and mental health regarding the unique needs of older persons in preparing for, and recovering from, disaster events.

Since social workers work with vulnerable populations on a daily basis, they serve an important role in disaster preparedness, response, and recovery. While social workers in the U.S. often are not specifically trained in disaster preparedness and response, their experiences in assessing community strengths and needs, crisis intervention, and their ability to organize disparate groups has prepared them to contribute to municipal disaster planning. Further, social workers account for $50 \%$ of responders post-disaster (Naturale, 2018) through both their existing roles and specific designation as disaster responders. As Torgusen and Kosberg (2008) said, "Social workers have always been seen as specially prepared for working with the victims of loss and trauma, including those resulting from disasters" (p. 31). Social workers interpret disaster context, advocate for effective services, and provide leadership in collaborations among organizations and larger institutions (National Association of Social Workers, 2015).

\section{Case Presentation}

Hurricane Charley was expected to strike Florida in approximately 24 hours. Diana Munoz was responsible for her 83-year-old father, Jose Munoz, who was diagnosed with Alzheimer's disease 3 years ago. The television was on and the weather broadcaster was urging people to evacuate the area. Mr. Munoz was agitated, disoriented, and continued repeating, "Where are you taking me? I don't want to leave home. I want to stay."

Ms. Munoz was unsure where the emergency shelter was located. She anticipated that the shelter would be loud, chaotic, and teeming with people who were in just as big of a crisis as she and her dad were facing. She was also concerned about the access to medical care for her father 
and professional available who understand dementia related behaviors that often exacerbated during stress. Her mother, who passed away 2 months ago, had been her father's primary caregiver. New as a caregiver, Ms. Munoz realized when packing that she only had 3 days' worth of her father's incontinence products and a limited supply of his numerous medications. The main thought playing over and over in her head was, "No one prepared me for this."

\section{Assessment and Intervention}

Disaster response, consistent with social work practice, is a holistic process that considers the biopsychosocial needs of individuals and their ecological systems, in preparing for, responding to, and recovering from disaster events (National Association of Social Workers, 2015). Disaster preparedness and response has three phases all of which include assessment and intervention: (1) planning for the disaster (pre-disaster); (2) disaster occurrence and immediate response/recovery (during and post-disaster); and, (3) disaster recovery (long-term disaster recovery. This section will highlight social workers' roles in these three phases using the case study to highlight each assessment and intervention phase.

\section{Stage 1: Pre-Disaster}

In pre-disaster assessment, social workers must consider the possibility that individuals are experiencing chronic conditions, limitations in activities of daily living (ADLs) and instrumental activities of daily living (IADLs), physical and cognitive disabilities, and/or sensory impairments (Aldrich \& Benson, 2008; Dyer, Regev, Burnett, Festa \& Cloyd, 2008; Weisler, Barbee \& Townsend, 2006). Risk factors include but are not limited to frailty, medical conditions (i.e., cognitive impairment, hearing or visual impairments and chronic illnesses), poverty, and the physical/built environment. Medication needs, special dietary needs, and medical supplies/equipment to manage health problems should also be identified because they 
lead to increased risk of illness, injury, or death during disasters for older adults (Acierno et al., 2006; Centers for Disease Control and Prevention, 2012; The Hartford Geriatric Education Center, 2011a; The Hartford Geriatric Education Center, 011b; World Health Organization, 2008; World Health Organization, 2013). In the case of Jose Munoz, his cognitive status, incontinence, and recent death of his wife are all risk factors in the natural disaster. His medication and incontinence supplies needs are also important.

Socially isolated older adults, even in large communities, are less apt to receive important warnings, ask for help, or evacuate, which can leave them "virtually invisible" to rescue and recovery efforts (Banks, 2013, p. 95). At the community level, social workers can help identify these vulnerable adults and develop and continually update a list of their names that first responders can use in the event of a natural disaster. Failure to assess these factors results in older adults experiencing greater mortality, morbidity, and functional decline than other populations in natural disasters (Banks, 2013). Given Diana's new role as a caregiver, and her father's agitation and disorientation due to Alzheimer's disease, including Mr. Munoz on a list of vulnerable adults would be advisable.

As well as assessing for risk factors and needs in planning for disasters, social workers should also assess the strengths of older adults. Consistently, research about older adults has shown that social relationships and support are strengths at both motivating older adults to plan for disasters and enhancing their safety and well-being post-disaster (Ashida, Robinson, Gay, \& Ramirez, 2016; Ashida, Zhu, Robinson \& Schroer, 2018; Eisenman, Cordasco, Asch, Golden \& Glki, 2007; Eisenman, Gonzalez, Maranon, Zhou, Tseng, \& Asch, 2009). Diana Munoz is a strong social support for her father despite the fact that she is new to her caregiving role following the death of her mother. As part of assessment, the social worker should identify ways 
to further educate and support Diana in her new role. Resiliency is also a protective factor for older adults post-disaster (Tuohy \& Stephens, 2012). In assessing Jose Munoz, the social worker would want to ask how he has managed other crises in his life.in order to determine his level of resiliency. For example, how has he coped with the death of his wife during the last two months? How has his cognitive status affected his ability to cope with the loss of his wife? How does this compare with the way he has dealt with crises prior to his diagnosis of Alzheimer's disease?

In pre-disaster intervention, social workers have roles in education about preparedness, establishment of support for disaster plans, organizational preparedness, and community planning. In a national sample of older adults focused on education about disaster preparedness, Al-Rousan and colleagues (2014) reported that older adults have not participated in any kind of educational program about disasters, most do not know where to find resources, and two-thirds of older adults do not have an emergency plan. Over one-third do not have basic supplies (e.g. food, water, medical supplies) available for emergencies, and about 14\% would need electricity to keep medical devices working. Diana Munoz and her father do not have an emergency plan in place. In fact, Diana has no knowledge regarding available resources, including emergency shelters, does not have adequate supplies to meet her father's medical needs, and does not feel prepared to respond adequately to natural disasters. Social workers can help caregivers like Diana Munoz to develop emergency plans for natural disasters using disaster preparedness materials provided by the American Red Cross (2009), the United States Department of Homeland Security (n. d.) and the Administration for Community Living (Fordyce, Kenny, \& Oettinger, 2006). 
Families and other informal supports play an important role in establishing support for disaster plans. Older adults living with family members, or who have supportive neighbors, are more likely prepared for disasters (Loke, Lai, \& Wai Man Fung, 2012). Kang (2014) found that older adults living with family members are better prepared with medications than those who live alone (e.g., Kang, 2014). With the assistance of family and friends, older adults can be empowered to take responsibility for disaster planning (Fernandez, Byard, Lin, Benson, \& Barbera, 2002). However, Tuohy and colleagues (2014) found that older adults living in the community sometimes assume family members will be willing and able to provide physical or financial care when this actually is not the case. Given this, a social worker involved with the Munoz family would establish that Diana is agreeable to an emergency plan and include both her and her father in developing the plan. The social worker should also identify other family members or neighbors who should be included in establishing support for the plan. Mobilizing neighbors is an area of untapped potential when planning for disasters because neighbors, in situations such as floods or fires, may be the people to help since families may not be able to access affected areas. Older adults can be empowered to engage with community associations and regional groups about disaster planning and evacuation needs (Banks, 2013).

Involvement in organizational preparedness for natural disasters is another role for social workers. Community plans for disaster preparedness should include health and aging services organizations, such as hospitals, home health care, assisted living facilities, and nursing homes. In home health care, plans for staff identification and access to disaster zones can be critical for providing in-home services during a disaster. Furthermore, back up plans for staffing, locating clients and remote records should be clearly articulated ahead of time (Christopher \& Goldstein, 
2014). The National Association for Home Care and Hospice (2008) has a toolkit to help home health agencies prepare.

Situations, including when 35 residents drowned at St. Rita's Nursing Home in Hurricane Katrina and the photo of assisted living residents up to their waists in water during Hurricane Harvey, illustrate the importance of proactive planning in these settings. In nursing homes, a "one-size-fits all" approach is not likely to work due to the varied biopsychosocial needs of residents. Claver and colleagues (2013) suggest that disaster plans should be designed to meet the specific needs of residents whether evacuating or sheltering in place. The use of a biopsychosocial framework as a foundation for evacuation planning may allow communities to adapt or tailor plans to population specific combinations of needs and risks. Nursing homes can harness the expertise of their social work staff in biopsychosocial assessment.

Successful organizational preparedness involves collaboration between long-term services and supports and community leaders to develop comprehensive plans. Healthcare providers, including social workers, should advocate for elder preparedness in their communities, share their knowledge to guide community leaders, and register with their state's professional response registry [e.g., Emergency System for Advance Registration of Volunteer Health Professionals (U.S. Department of Health \& Human Services, n. d.)], so they can be available during an emergency (Banks, 2013). In addition, community level disaster plans should take into account the impact of evacuation and relocation on the health and well-being of older adults (Elmore \& Brown, 2007).

Community planning for most disaster preparedness occurs locally because in disasters the local community responds until outside help arrives. According to Elmore and Brown (2007), the planning process itself is important for fostering relationships across diverse 
stakeholder groups because these relationships can be helpful if disaster strikes. Planning should include experts from aging services, such as the U.S. Administration on Aging, state aging units, area agencies on aging, Native American tribal organizations, and local providers, consumers, and caregivers (Administration for Community Living, 2018; Elmore \& Brown, 2007). Planning should also include coordination among aging services, clarification about roles at the local, state, and federal levels, and drills to ensure responders can quickly meet the needs of vulnerable groups (Pekovic, Seff, \& Rothman, 2007). Social workers should help develop realistic disaster plans and drills to ensure settings are as prepared as can be and to avoid the bureaucratic shuffle of disaster planning (Disaster Preparedness and Response, 2017), where plans are filed without re-evaluating changing individual and family needs, staff availability, and resources. Just as older adults' emergency plans need to be individualized, organizations and communities should have customized plans tailored to their needs, risks, and existing resources.

\section{$\underline{\text { Stage 2: During and Post-Disasters }}$}

Post-disaster assessment includes (1) addressing immediate needs post-disaster and responding and (2) assessing the impact of displacement and relocation. $\underline{\text { In addressing immediate }}$ needs and responding, social workers have unique responsibilities when caring for older adults and their families. Similar to planning for a disaster, what occurs during any disaster at the individual and family level looks different for older adults depending on family circumstances. Simultaneously, it is important for emotional well-being and recovery that social workers remind individuals and families that they need to maintain as much normalcy and routine as possible (Naturale, 2018). In an active rescue situation, the resources needed to rescue a family with an older adult may be different from those needed for an older person who is isolated or coping alone. 
Social isolation is a significant problem for older adults particularly during disasters when the services and supports on which they rely are likely to be disrupted (Chandra et al., 2018). As previously discussed, older adults who are alone and isolated may have less ability to address their own needs. Seniors are more likely to respond to mandatory evacuation orders than voluntary evacuation requests (Gray-Graves, Turner, \& Swan, 2011). There are many reasons that an older person might choose not to evacuate. One reason is the desire to stay with one's pets. Many individuals will elect to stay at home with pets if they do not have the means to transport or shelter with their animals (Torgusen \& Kosberg, 2008). Other reasons include: health conditions; lack of accessible transportation; lack of finances; mobility issues due to chronic issues and/or disability; social supports; history of not evacuating in the past; or desire to avoid staying in shelters or other places where needs may not be met (e.g., Taylor, Priest, Sisco, Banning, \& Campbell, 2009; Rosenkoetter, Covan, Bunting, Cobb, \& Fugate-Whitlock, 2007). Displacement and relocation are common outcomes of disasters. Age-related changes make older persons particularly vulnerable to the adverse effects of relocation (Pekovic et al., 2007; Sanders, Bowie \& Bowie, 2003). Relocation can trigger long-term stressors, such as interruption of the older person's lifestyle, relationships, community connections, and sense of safety (Chao, 2017). In fact, relocation may be more dangerous to the older person's well-being than the disaster itself (Chao, 2017; Norris, Friedman, \& Watson, 2002). While some older adults can go home after post-disaster rebuilding, they often permanently relocate (Binder, Baker $\&$ Barile, 2015). Social workers need to be aware of these effects when a senior arrives in their community due to a disaster event.

Post-disaster interventions include establishing shelters, acting as responders, and residential decision-making. When deciding to evacuate or shelter in place, older adults need to 
consider the perceived threat to their location, where they would go as an alternative (i.e., an established shelter) and how to get there. This information should be readily available by the community to help inform older adults who may be reliant on social supports or external resources. Social workers should advocate for community education regarding resources available in shelter and disaster recovery settings that accommodate older persons and should educate entities about the needs of older persons in such settings (e.g., chronic conditions; need for emergency access to medication; life-sustaining medical equipment that runs on power) (Gibson, 2016).

Often social workers are disaster responders by default because they work in an affected area. After Hurricane Katrina, New Orleans senior center staff discussed their responses. They told a story about how, upon reopening the center, they had to drive around town trying to find their seniors to determine if the clients were safe, had left town, or had perished in the storm (Croom \& Jenkins, 2007). During heat waves, case managers often contact their clients, even on weekends, to determine if they are able to access safe spaces and/or cooling equipment to prevent heat stroke.

Home health care is essential during a disaster: "During and immediately following natural disasters ... caregivers are the unsung heroes; usually responding before the first responders by choosing to stay with their clients to see them through to safety-even when it means not going home" (Poo, 2015, p. 83). Home health agencies also provides vital information about older adults in the community. Visiting Nurse Service of New York was prepared for Superstorm Sandy because of robust disaster planning and a designated incident response system. One of their essential pieces was a system in which each patient received a priority designation that considered a patient's medical conditions, whether they lived alone, and the 
level of risk without aide service. This allowed them to support patients during the storm and anticipate transit disruptions that limited staff abilities to reach their patients (Christopher \& Goldstein, 2014).

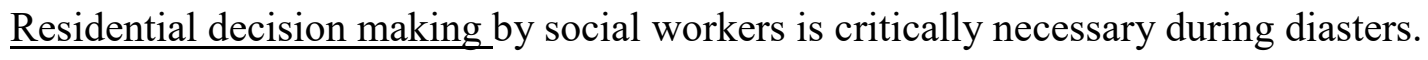
Older adults in nursing homes may be the most vulnerable during disasters since they are often the frailest. Nursing homes face the same critical decision as other systems, which is to evacuate or shelter in place (Dosa, Hyer, Brown, Artenstein, Polivka-West, \& Mor, 2008). They also have to assess the same conditions, such as safety, power, food, medicine, and transportation, made more difficult by complex resident needs, including end-of-life care needs (Frahm \& Brown, 2011). Residents rely on staff to make decisions for them in crises, yet staff often are not trained in disaster decision making. Claver et al. (2013) examined lessons learned by Veterans Affairs' nursing homes during disaster evacuations and found staff were not told which patients to evacuate first. Each home made their own decision, with one evacuating the sickest first and another evacuating the healthiest, which made it harder to secure transportation for sicker patients later in the evacuation. Another found evacuation equipment they had been issued was useless when they needed it because no one had tried it out beforehand and discovered too late that it was not appropriate for the circumstances (Claver et al., 2013). Social work involvement in conducting well-crafted disaster drills could have helped anticipate this problem and resolve it in advance of the disaster.

\section{Step 3: Long Term Disaster Recovery}

Long term disaster recovery assessment includes assessing and treating traumatic stress, assessing financial stress, and community assessment. In assessing and treating traumatic stress immediately post-disaster, social workers, should offer a "compassionate presence" to older 
persons recovering from the grief and trauma of the disaster (Naturale, 2018). Social workers must be familiar with disaster mental health trends and cultural considerations that may accompany traumatic response in older adults, such as how exposure to a disaster increases risk for posttraumatic stress disorder (PTSD) (e.g., Galea, Tracy, Norris, \& Coffey, 2008; Pietrzak, Goldstein, Southwick, \& Grant, 2012). While many disaster survivors experience temporary distress, a small percentage ( $6 \%-20 \%)$, without appropriate intervention, continue to experience debilitating trauma symptoms associated with PTSD (Breslau, Kessler, Chilcoat, Schuktz, Davis, \& Andreski, 1998; Brewin, Rose, \& Andrews, 2002; Kessler, Sonnega, Bromet, Hughes, \& Nelson, 1995). Social workers need to be prepared to refer or provide older populations with evidence-based PTSD treatment such as Cognitive Processing Therapy and Prolonged Exposure Therapy (Cox \& D’Oyley, 2011; Jeffreys, Reinfeld, Nair, Garcia, MataGalan, \& Rentz, 2014; Lopes, Macedo, Coutinho, Figueira, \& Ventura, 2014) and Acceptance and Commitment Therapy (ACT; Petkus \& Wetherell, 2013). However, while there are numerous evidence-informed treatments available for conditions that can result from mass trauma, few studies have tested these interventions on older adults (Gibson, Walsh, \& Brown, 2017).

Assessing financial stress is important because it can affect the emotional well-being of older adults and their families during long-term disaster recovery. Older adults are more likely to suffer significant financial losses after disaster than younger groups (Al-Rousan et al., 2014). They are less able to absorb disaster-related expenses and more likely than younger adults to incur such costs. Due to preexisting financial constraints, older adults are more likely to live in dilapidated older homes that are more vulnerable to the effects of natural disasters and less likely to be able to afford needed repairs (Powell et al., 2009). Unlike younger adults who have time to 
rebuild, older adults have shorter time horizons and ability to recoup losses (Walsh, Gibson, \& Brown, 2016). Social workers are well-suited to assist older adults in identifying resources to address financial need, and to advocate for federal and state programs that can assist this unique need among the aging population.

Just as community assessments are conducted at the pre-and immediate-recovery stages of disaster, community assessments should be conducted post-disaster to analyze the needs of individuals and the larger community. With particular consideration to community assessment, social workers should work on interprofessional teams to evaluate the needs of older persons in their community and determin if the disaster has resulted in service limitations or other restrictions negatively impacting community residents (e.g., Gibson \& Hayunga, 2006).

Long-term disaster recovery interventions include coping with community loss, physical rebuilding of the community, and building community resilience. Community loss is measured in physical damage and financial loss. However, a community often experiences shared grief. Immediately post-disaster, communities tend to unite. After the September 11, 2001 terrorist attacks, the U.S. rallied around the phrase, "United We Stand." But even with the outpouring of unity, when communities begin having conversations about using funds for recovery, building, and planning memorials, these political, bureaucratic discussions can become conflictual (Shughart, 2006) and communities that were once bonded through the disaster can splinter into factions each considering their own best interest. Social workers may need to provide conflict resolution for these community conversations.

In severe damage, the physical rebuilding of communities is necessary. Structures that house or support older adults need to be renovated or rebuilt. In October 2015, South Carolina had a historic 1000-year flood. Much of the southeastern part of the state experienced 20 to 24 
inches of rain in 120 hours. In February 2016, a regional hospital in Kingstree, South Carolina closed due to mold that developed from extensive water damage. Until replacement services were established, many residents had to travel 25 to 30 or more miles for emergency services (Brown, 2016; Carr, Bowman, Wolff, Mullen, Holena, \& Wiebe, 2017). This distance could be life or death for an older person with a chronic illness or experiencing an acute medical emergency. Further, older adults with limited transportation and financial burdens experience additional barriers to access these services. Social workers should consider these issues and help identify solutions when working with older adults post-disaster.

Building community resilience and enhancing communities to reduce the negative impacts of disasters supports the well-being of older adults. Community resilience expands the traditional preparedness approach by encouraging actions that build preparedness while promoting strong community systems and addressing the many factors that contribute to health. While communities tend to consider community resilience following a disaster, social workers should facilitate conversations about community resilience in the disaster planning stages, and during long-term post disaster recovery (Chandra et al., 2018).

\section{Future Steps for Research, Policy and Practice}

Research: Social work researchers conducting studies about disaster response and recovery can have challenges to ensuring rigorous approaches are used, but there are preemptive strategies that can be taken to ensure quality research (e.g., having an Institutional Review Protocol approved prior to a disaster event when possible, deploying multiple researchers to ensure ample information is gathered post-disaster). There is an urgent need for this research to enhance services and supports for older adults affected by disasters (e.g., Gibson \& Hayunga, 2006). First, there is a need for more inclusion of practices that are rooted in evidence. Many of 
the approaches utilized in disaster response have limited evidence to support them as best practice. This is especially true for older adults because what limited evidence there is does not include research done with older populations (Gerdin et al., 2014; Gibson, Walsh \& Brown, 2017; Mahapatra, 2014). Second, research should look to better understand older adults' motivations, behaviors, and experiences of disaster planning and response. Many disaster response and recovery organizations (e.g., American Red Cross) have implemented scientific advisory councils to assist in ensuring planning and response efforts include evidence-based and best practice approaches (American Red Cross, n.d.). Third, there is a need to build on existing interventions to best determine how they could be adapted to be more efficient or to serve other diverse older adult groups, or be implemented utilizing varying approaches (e.g., an online tool or as a group intervention). As research continues to suggest that older adults have diverse needs in disaster events, social workers need to advocate for the inclusion of diverse perspectives in disaster planning and response so that disaster responders and mental health professionals consider cultural differences and individualized needs for disaster support and services among the aging population.

Finally, it is important that social work researchers take part in interdisciplinary teams conducting disaster-related research across the country. Multiple agencies, such as the National Science Foundation, the National Institutes of Health, and the National Oceanic and Atmospheric Administration, have calls for proposals to address disaster risks and impacts, and these teams include engineers, emergency managers, community planners, and policy makers. As key members of these teams, social workers can ensure that the needs of older adults and individuals with disabilities are considered and that best practices are identified and utilized when designing disaster response and recovery plans. 
Policy: With each new natural disaster, policies are introduced to better prepare for, and mitigate the effects of, disasters. In some communities, older adults and those with disabilities can sign up for a registry so that emergency operations managers know where they are and what they may need in an emergency. For example, in Rhode Island, enrolling in the registry ensures that first responders and emergency management officials can identify those who may need assistance during a disaster (Rhode Island Department of Health, 2018). Social workers interacting with community-dwelling older adults can help to ensure socially isolated individuals, particularly those who have any of the identified risk factors for serious threats to health and safety during a disaster, sign up for these types of registries (Elmore \& Brown, 2007). While government entities are strongly encouraged to implement these registries, individuals in areas highly prone to disasters are reluctant to sign up because they do not self-identify as having "special needs" or "assistance needs" (Gibson \& Hayunga, 2006; Renne, Sanchez, \& Litman, 2008). While assistance registries are excellent for identifying individuals in the case of emergency, they do not guarantee priority access in response and recovery (i.e., priority power restoration). Thus, it is even more essential for social workers to assist in identifying high-risk individuals in the community to ensure they have an individualized plan for disaster preparedness and recovery.

On the federal level, the U.S. Congress introduced a bill to help encourage those in affected disaster areas, including older adults, to evacuate with the passage of the Pet Evacuation Transportation Standards (PETS) Act of 2006. Following Hurricane Katrina, the PETS Act authorized the Federal Emergency Management Agency (FEMA) to provide rescue, care, shelter, and essential needs for individuals with household pets and service animals as well as household pets (The White House, 2005). While this supports the facilitation of pets in the evacuation 
process, social workers must continue to advocate for the inclusion of pets in evacuation and shelter planning (Banks, 2013).

Social workers should help to develop additional policies to support older adults affected by disasters, such as: requiring disaster planning and response efforts to adopt and implement evidence-based approaches to disaster risk reduction; to develop policies targeting environmentally induced migration and population displacement; and to strengthen equityoriented resilience policies and proactively engage marginalized communities in adaptation planning within both urban and rural areas (Sears, Kemp \& Palinkas, 2017).

Practice: Many social workers feel unprepared to respond in the immediate aftermath of disasters. Some social workers have only learned about the role of social work in disasters first hand when their communities are affected by disaster events. Continuing education trainings that review disaster planning and response will enhance the social work profession's capacity to assist in preparing and responding disasters. Social workers should share stories about their experiences in disaster planning, response, and recovery. The social work profession needs firsthand accounts about what happened, what went well in a disaster, and what did not go well. Learning from mistakes will provide guidance about best practices for assisting older adults in disasters. The importance of having well-trained and aging competent professionals to support older adults affected by disasters cannot be overstated. .

Further, social workers should educate and support older adults in disaster preparedness. Social workers often help older adults and their families plan and prepare for disasters through psychoeducation. One such approach, PrepWise, is a disaster preparedness training program specifically for older adults (see Ashida, Robinson, Gay, Slagel, \& Ramirez, 2017). The program instructs older adults to complete a personal and household assessment, develop a 
personal emergency network, compile emergency information and important documents, keep an emergency supply of medications and medical supplies, and build an emergency kit. In a study by Ashida and colleagues (2017), following participation in the PrepWise program, rural older adult participants on average identified three new sources of emergency support.

\section{Conclusion}

Social workers can learn from the experiences of those affected by past disasters as well as other social workers that have worked with clients affected by disasters. Social workers have the training, knowledge, and experience to advocate for the unique needs of older adults disproportionately affected by the environment, and need to take on this important challenge.

\section{$\underline{\text { Discussion Questions }}$}

1. What are the risk factors, needs, and strengths of older adults in disasters? Do social workers have the skills to assess and address them?

2. Explain diversity factors of older adults that might affect their needs during a disaster.

3. Compare and contrast the needs of older adults in disaster events with those of the general population (i.e., adults \& children)

4. A family caregiver of an older adult comes to you to ask for help in preparing for a disaster. What tips and resources would you provide to help them prepare for disasters with their loved one?

5. What is important for nursing homes to consider in preparing for, and responding to, disasters?

6. How would you suggest that social workers get involved in disaster preparation and response in their communities?

7. Find a recent news story that addresses issues of older adults during disasters. Based on the information in this chapter, identify 2 to 3 ideas that could have helped prevent the issues faced during the event. 


\section{References}

Acierno, R., Ruggiero, K. J., Kilpatrick, D. G., Resnick, H. S. \& Galea, S. (2006). Risk and protective factors for psychopathology among older versus younger adults after the 2004 Florida hurricanes. American Journal of Geriatric Psychiatry, 14(12), 1051-9. doi:10.1097/01.JGP.0000221327.97904.b0

Administration for Community Living. (2018). Emergency preparedness. Retrieved from https://www.acl.gov/programs/emergency-preparedness

Al-Rousan, T. M., Rubenstein, L. M., \& Wallace, R. B. (2014). Preparedness for natural disasters among older US adults: A nationwide survey. American Journal of Public Health, 104(3), 506-511. doi:10.2105/AJPH.2013.301559

Aldrich, N., \& Benson, W.F. (2008). Disaster preparedness and the chronic disease needs of vulnerable older adults. Centers for Disease Control and Prevention. Retrieved from http://www.cdc.gov/pcd/issues/2008/jan/pdf/07_0135.pdf.

American Red Cross. (2009) Disaster preparedness for seniors by seniors. Retrieved from http://www.redcross.org/images/MEDIA_CustomProductCatalog/m4640086_Disaster_Pr eparedness_for_Srs-English.revised_7-09.pdf

American Red Cross (n.d.). The science behind our programs. Retrieved from https://www.redcross.org/take-a-class/scientific-advisory-council.

Ashida, S., Robinson, E.L., Gay, J., \& Ramirez, M. (2016). Motivating rural older residents to prepare for disasters: Moving beyond personal benefits. Ageing \& Society, 36(10), $2117-$ 2140. doi:10.1017/S0144686X15000914

Ashida S., Robinson E.L., Gay J., Slagel, L.E., \& Ramirez M.R. (2017). Personal disaster and emergency support networks of older adults in a rural community: Changes after 
participation in a preparedness program. Disaster Medicine and Public Health Preparedness, 11(1), 110-119. doi:10.1017/dmp.2016.197

Ashida, S., Zhu, X., Robinson, E.L., \& Schroer, A. (2018). Disaster preparedness networks in rural Midwest communities: Organizational roles, collaborations, and support for older residents. Journal of Gerontological Social Work, 61(7), 735-750. doi:

$10.1080 / 01634372.2018 .1474157$

Banks, L. (2013). Caring for elderly adults during disasters: Improving health outcomes and recovery. Southern Medical Journal, 106(1), 94-98. doi:

10.1097/SMJ.0b013e31827c5157

Binder, S.B., Baker, C.K., \& Barile, J.P. (2015). Rebuild or relocate? Resilience and post disaster decision-making after Hurricane Sandy. American Journal of Community Psychology, 56(1-2):180-196. doi: 10.1007/s10464-015-9727-x.

Breslau, N., Kessler, R.C., Chilcoat, H.D., Schultz, L.R., Davis, G.C., \& Andreski, P. (1998). Trauma and posttraumatic stress disorder in the community: The 1996 Detroit Area Survey of Trauma. Archive of Geriatric Psychiatry, 55, 626-632. doi:10.1001/archpsyc.55.7.626

Brewin, C., Rose, S., \& Andrews, B. (2002). Screening to identify individuals at risk after exposure to trauma. In U. Schneider. (Ed.), Early intervention for psychological trauma. (pp. 130-142). Oxford, England: Oxford University Press.

Brown, B. (2016, October 27). 1,000 year flood, One Year later. Lessons learned. South Carolina Rural Healthcare annual meeting. Hilton Head Island, SC.

Carr, B.G., Bowman, A.J., Wolff, C.S., Mullen, M.T., Holena, D.N., \& Wiebe, D.J. (2017). Disparities in access to trauma care in the United States: A population-based analysis. 
Retrieved from https://www.ncbi.nlm.nih.gov/pubmed/28069138

Centers for Disease Control and Prevention (2012). Disaster planning tips for older adults and their families. Retrieved from http://www.cdc.gov/aging/pdf/disaster_planning_tips.pdf

Centers for Disease Control. (2006). CDC's disaster planning goal: Protect vulnerable older adults. Retrieved from http://www.cdc.gov/aging/pdf/disaster_planning_goal.pdf.

Chandra, A., Acosta, J., Stern, S., Uscher-Pines, L., Williams, M.V., Yeung, D., ,.. Meredith, L.S. (2018). Building community resilience to disasters. RAND Health. Retrieved from https://www.rand.org/content/dam/rand/pubs/technical_reports/2011/RAND_TR915.pdf

Chao, S. (2017). Social support, coping strategies and their correlations with older adults' relocation adjustments after natural disaster. Geriatrics \& Gerontology International, 17, 1006-1014. doi: 10.1111/ggi.12807

Christopher, M.A., \& Goldstein, J. (2014). The Visiting Nurse Service of New York's response to Hurricane Sandy. The American Journal of Nursing, 114(10), 55-62. doi:10.1097/01.NAJ.0000454857.90630.dc

Claver, M., Dobalia, A., Fickel, J.J., Ricci, K.A., \& Mallers, M.H. (2013). Comprehensive care for vulnerable elderly veterans during disaster. Archives of Gerontology and Geriatrics, 56, 205-213. doi: 10.1016/j.archger.2012.07.010

Cox, D., \& D'Oyley, H. (2011). Cognitive-behavioral therapy with older adults. British Columbia Medical Journal, 53, 348-352.

Croom, C., \& Jenkins P.J. (2007). The story of the senior center: Meeting immediate needs. Generations, 31(4). 47-48.

Disaster Preparedness and Response: The Special Needs of Older Americans, Senate, 115th 
Cong. 4 (2017) (Testimony of Kathryn Hyer and David Dosa).

Dosa, D. M., Hyer, K., Brown, L. M., Artenstein, A. W., Polivka-West, L., \& Mor, V. (2008). The controversy inherent in managing frail nursing home residents during complex hurricane emergencies. Journal of the American Medical Directors Association, 9(8), 599-604. doi: 10.1016/j.jamda.2008.05.007

Dyer, C.B., Regev, M., Burnett, J., Festa, N., \& Cloyd, B. (2008). SWiFT: A rapid triage tool for vulnerable older adults in disaster situations. Disaster Med Public Health Prep, 2(S1), S45-50. doi:10.1097/DMP.0b013e3181647b81

Eisenman, D.P., Cordasco, K.M., Asch, A., Golden, J.F., \& Glik, D. (2007). Disaster planning and risk communication with vulnerable communities: Lessons from Hurricane Katrina. American Journal of Public Health, 97(S1), S109-S115. doi:10.2105/AJPH.2005.084335

Eisenman D.P., Glik D., Gonzalez, L., Maranon, R., Zhou, Q., Tseng, C.H., \& Asch, S.M. (2009). Improving Latino disaster preparedness using social networks. American Journal of Preventive Medicine, 37(6), 512-7. doi: 10.1016/j.amepre.2009.07.022

Elmore, D., \& Brown, L. (2007). Emergency preparedness and response: Health and social Policy implications for older adults. Generations, 31(4), 66-74.

Fernandez, L. S., Byard, D., Lin, C. C., Benson, S., \& Barbera, J. A. (2002). Frail elderly as disaster victims: Emergency management strategies. Prehospital Disaster Medicine, 17(2), 67-74. doi:10.1017/S1049023X00000200

Fordyce, E.N., Kenny, D.E., \& Oettinger, E. (2006). Just in case: Emergency readiness for older adults and caregivers. U.S. Department of Health \& Human Services, Administration on Aging. Retrieved from https://www.acl.gov/sites/default/files/programs/201610/Just in_Case030706_links.pdf 
Frahm, K.A., \& Brown, L.M. (2011). The importance of end-of-life care in nursing home settings is not diminished by disaster. OMEGA, 64(2), 143-155. doi: 10.2190/OM.64.2.c

Galea, S., Tracy, M., Norris, F., \& Coffey, S.F. (2008). Financial and social circumstances and The incidence and course of PTSD in Mississippi during the first two years after Hurricane Katrina. Journal of Traumatic Stress, 21, 357-368. doi: 10.1002/jts.20355

Gerdin, M., Clarke, M., Allen, C., Kayabu, B., Summerskill, W., Devane, D., ... von Shreeb, J. (2014). Optimal evidence in difficult settings: Improving health interventions and decision making in disasters. PLoS Medicine, 11(4), e1001632. doi: 10.1371/journal.pmed.1001632.

Gibson, A. (2016, November). Stories from the flood: Dementia caregivers' disaster response training recommendations. In A. Gibson (Chair). Disaster preparedness for older adults: Best practices in training. Symposium conducted at the meeting of the Gerontological Society of America, New Orleans, LA.

Gibson, A., Walsh, J., \& Brown, L.M. (2017). Disaster mental health services review of care for older persons following disasters. Disaster Medicine and Public Health Preparedness. Advance online publication. doi: 10.1017/dmp.2017.60.

Gibson, M.J., \& Hayunga, M. (2006). We can do better: Lessons learned for protecting older persons in disaster. Washington, DC: AARP. Retrieved from https://assets.aarp.org/rgcenter/i1/better.pdf.

Gray-Graves, A., Turner, K.W., \& Swan, J.H. (2011). The level of willingness to evacuate among older adults. Gerontology \& Geriatric Education, 32(2), 107-121. doi:10.1080/02701960.2011.572034.

Jeffreys, M.D., Reinfeld, C., Nair, P.V., Garcia, H.A., Mata-Galan, E., \& Rentz, T.O. (2014). 
Evaluating treatment of posttraumatic stress disorder with cognitive processing therapy and prolonged exposure therapy in a VHA specialty clinic. Journal of Affective Disorder, 28, 108-114. doi: 10.1016/j.janxdis.2013.04.010

Kang, K. (2014). Disaster preparedness among vulnerable older adults with chronic diseases: Results from a cross-sectional study in Incheon, Korea. Nursing \& Health Sciences, 16(1), 46-51. doi: 10.1111/nhs.12133

Kessler, R.C., Sonnega, A., Bromet, E., Hughes, C.B., \& Nelson, M. (1995). Posttraumatic stress disorder in the National Comorbidity Survey. Archives of Geriatric Psychiatry, 52, 1048-1060. doi:10.1001/archpsyc.1995.03950240066012

Loke, A.Y., Lai, C.K.Y., \& Wai Man Fung, O. (2012). At-home disaster preparedness of elderly people in Hong Kong. Geriatrics \& Gerontology International, 12, 524-531. doi: $10.1111 / j .1447-0594.2011 .00778 . x$

Lopes, A.P., Macedo, T.F., Coutinho, E.S.F., Figueira, I., \& Ventura, P.R. (2014). Systematic review of the efficacy of cognitive-behavior therapy related treatments for victims of natural disasters: A worldwide problem. PLOS One, 9(10), e109103. doi:10.1371/journal.pone.0109013

Mahapatra, P. (2014). The need for evidence-based public health response in disasters. Journal of Evidence-Based Medicine, 7(4), 238-244. doi: 10.1111/jebm.12129.

Monahan, K. \& Lurie, A. (2007). Reactions of senior citizens to 9/11: Exploration and practice guidelines for social workers. Social Work in Health Care, 45(1), 33-47.

Mooney, C. \& Dennis, B. (2018, January 8). Extreme hurricanes and wildfires made 2017 the most costly U.S. disaster year on record. The Washington Post. Retrieved from http://washingtonpost.com. 
Murdock, S.H., Cline, M.E., Zey, M., Perez, D., Jeanty, P.W. (2015). Population change in the United States. New York, NY: Springer.

National Association for Home Care and Hospice (2008). Emergency preparedness packet for home care agencies. Retrieved from http://www.nahc.org/wp-content/uploads/2017/10/EP_Binder.pdf

National Association of Social Workers. (2015). Disasters. Social work speaks: National Association of Social Workers policy statements, 2015-2017. (10th ed.). Washington DC: NASW Press.

National Oceanic and Atmospheric Administration (2018). Billion-dollar weather and climate disasters. Retrieved from https://www.ncdc.noaa.gov/billions/.

Naturale, A. (2018, March). New evidence informed intervention approaches for social workers responding to natural disasters and other mass casualty events. Paper presented at the Social Work Hospice \& Palliative Care Network annual meeting. Boston, MA.

Nedelman, M. (2017, October 17). A series of deadly disasters for the elderly. CNN. Retrieved from https://www.cnn.com

Norris, F. H., Friedman, M. J., \& Watson, P. J. (2002). 60,000 disaster victims speak: Part II. Summary and implications of the disaster mental health research. Psychiatry, 65(3), 240260. doi: $10.1521 /$ psyc. 65.3 .240 .20169

Pekovic, V., Seff, L., \& Rothman, M.B. (2007-2008). Planning for and responding to special needs of elders in natural disasters. Generations, 31(4), 37-41.

Petkus, A.J., \& Wetherell, J.K. (2013). Acceptance and commitment therapy with older adults: Rationale and considerations. Cognitive Behavioral Practice, 20(1), 47-56. doi:10.1016/j.cbpra.2011.07.004 
Pietrzak, R.H., Goldstein, R.B., Southwick, S.M., \& Grant, B.F. (2012). Psychiatric comorbidity of full and partial posttraumatic stress disorder among older adults in the United States: Results from wave 2 of the National Epidemiologic Survey on Alcohol and Related Conditions. Journal of the American Geriatric Society, 20, 380-390. doi:10.1097/JGP.0b013e31820d92e7

Poo, A-J. (2015). The age of dignity: Preparing for the elder boom in a changing America. New York, NY: The New Press.

Powell, S., Plouffe, L., \& Gorr, P. (2009). When ageing and disasters collide: Lessons from 16 international case studies. Journal of Radiological Protection, 134, 202-206. doi: $10.1093 / \mathrm{rpd} / \mathrm{ncp} 082$

Renne, J.L., Sanchez, T.W., \& Litman, T. (2008). National study on carless and special needs evacuation planning: A literature review. Planning and Urban Studies Reports and Presentations. Retrieved from http://scholarworks.uno.edu/plus_rpts/8.

Rhode Island Department of Health. (2018). Rhode Island Special Needs Emergency Registry. Retrieved from http://www.health.ri.gov/emergency/about/specialneedsregistry/index.php.

Rosenkoetter, M.M., Covan, E.K., Bunting, S.; Cobb, B.K., \& Fugate-Whitlock, E. (2007). Disaster evacuation: An exploratory study of older men and women in Georgia and North Carolina. Journal of Gerontological Nursing, 33(12), 46-54.

Sakauye, K.M., Streim, J.E., Kennedy, G.J., Kirwin, Llorente, Schultz, et al., (2009). AAGP position statement: Disaster preparedness for older Americans: critical issues for the preservation of mental health. Journal of American Geriatric Society, 17, 916e24.

Sanders, S., Bowie, S.L., \& Bowie, Y.D. (2003). Chapter 2 lessons learned on forced relocation of older adults: The impact of Hurricane Andrew on health, mental health, and social 
support of public housing residents. Journal of Gerontological Social Work, 40(4), 23-25. doi: 10.1300/J083v40n04_03

Sears, J., Kemp, S., \& Palinkas, L. (2017). Develop policies targeting environmentally induced displacement in the United States. (Policy Action Statement). American Academy of Social Work and Social Welfare. Retrieved from https://aaswsw.org/wpcontent/uploads/2017/03/PAS.7.1.pdf

Shughart, W.F. (2006). Katrinanomics: The politics and economics of disaster relief. Public Choice, 127, 31-53. doi: 10.1007/s11127-006-7731-2

Taylor, K., Priest, S., Sisco, Banning, H.F., \& Campbell, K. (2009). Reading hurricane Katrina: Information sources and decision making in response to a natural disaster. Social Epistemology, 23(3-4), 361-380.

The Hartford Geriatric Education Center (2011a). It could happen to me: Family conversations about disaster planning. Retrieved from http://www.thehartford.com/mature-market-excellence/disaster-planning.

The Hartford Geriatric Education Center (2011b). The calm before the storm: Family conversations about disaster planning, caregiving, Alzheimer's Disease and dementia. Retrieved from http://hartfordauto.thehartford.com/UI/Downloads/CalmBeforeStormBro.pdf. The White House (2005). Katrina lessons learned. Chapter 5. Retrieved from https://georgewbush-whitehouse.archives.gov/reports/katrina-lessonslearned/chapter5.html.

Torgusen, B.L., \& Kosberg, J.I. (2008). Assisting older victims of disasters. Journal of Gerontological Social Work, 47(1-2), 27-44. doi: 10.1300/J083v47n01_04 
Tuohy, R., \& Stephens, C. (2012). Older adults' narratives about a flood disaster: Resilience, coherence, and personal identity. Journal of Aging Studies, 26(1), 26-34. doi:10.1016/j.jaging.2011.06.002

Tuohy, R., Stephens, C., \& Johnston, D. (2014). Qualitative research can improve Understandings about disaster preparedness for independent older adults in the community. Disaster Prevention and Management, 23(3), 296-208. doi: 10.1108/DPM01-2013-0006

United Nations (2018). Global issues: Ageing. Retrieved from http://www.un.org/en/sections/issues-depth/ageing/.

United Nations Office for Disaster Risk Reduction (2015). Disaster statistics. Retrieved from https://www.unisdr.org/we/inform/disaster-statistics.

United States Department of Health \& Human Services. (n. d.). Emergency System for Advance Registration of Volunteer Health Professionals. Retrieved from https://www.phe.gov/esarvhp/pages/about.aspx

United States Department of Homeland Security. (n.d.) Seniors. Retrieved from https://www.ready.gov/seniors.

Walsh, J., Gibson, A., \& Brown, L.M. (2016). Peace of mind's price tag: The psychological costs of financial stressors on older adults' post-disaster. Translational Issues in Psychological Science, 2(4), 408-417.

Weisler, R.H., Barbee, J.G., \& Townsend, M.H. (2006). Mental health and recovery in the Gulf Coast after Hurricanes Katrina and Rita. Journal of the American Medical Association, 296(5), 585-588. doi:10.1001/jama.296.5.585

World Health Organization (WHO) 2008. Older persons in emergencies: An active ageing 
perspective. Retrieved from

http://www.who.int/ageing/projects/emergencies/en/.

World Health Organization (WHO) 2013. Older persons in emergency situations: A case study of the Great Hanshin-Awaji Earthquake. Retrieved from http://www.who.int/kobe_centre/publications/Technical_report_OlderPersons_Emergenc y_Situations_GHAE_19MAR13_final.pdf?ua $=1$. 